\title{
RecurrenceOnline: an online analysis tool to determine breast cancer recurrence and hormone receptor status using microarray data
}

\author{
Balázs Győrffy · Zsombor Benke • András Lánczky • \\ Bálint Balázs · Zoltán Szállási · József Timár • \\ Reinhold Schäfer
}

Received: 5 May 2011/Accepted: 6 July 2011 / Published online: 16 July 2011

(C) Springer Science+Business Media, LLC. 2011

\begin{abstract}
In the last decades, several gene expressionbased predictors of clinical behavior were developed for breast cancer. A common feature of these is the use of multiple genes to predict hormone receptor status and the probability of tumor recurrence, survival or response to chemotherapy. We developed an online analysis tool to compute ER and HER2 status, Oncotype DX 21-gene recurrence score and an independent recurrence risk classification using gene expression data obtained by interrogation of Affymetrix microarray profiles. We implemented rigorous quality control algorithms to promptly exclude any biases related to sample processing, hybridization and scanning. After uploading the raw microarray data, the system performs the complete evaluation automatically and provides a report summarizing the results. The system is accessible online at http://www.recurrenceonline.com. We validated the system using data from 2,472 publicly
\end{abstract}

B. Győrffy $(\bowtie) \cdot$ R. Schäfer

Laboratory of Functional Genomics, Charité, Charitéplatz 1, 10117 Berlin, Germany

e-mail: gyorffy@recurrenceonline.com

B. Győrffy · Z. Benke · A. Lánczky · B. Balázs

Research Laboratory for Pediatrics and Nephrology,

Hungarian Academy of Sciences, Budapest, Hungary

Z. Benke · A. Lánczky · B. Balázs

Pázmány Péter University, Faculty of Informatic Technology,

Budapest, Hungary

Z. Szállási

Children's Hospital Informatics Program, Harvard Medical

School, Boston, USA

J. Timár

2nd Department of Pathology, Semmelweis University,

Budapest, Hungary available microarrays. The validation of the prediction of the 21-gene recurrence score was significant in lymph node negative patients (Cox-Mantel, $P=5.6 \mathrm{E}-16, \mathrm{HR}=0.4$, $\mathrm{CI}=0.32-0.5)$. A correct classification was obtained for $88.5 \%$ of ER- and $90.5 \%$ of ER + tumors $(n=1,894)$. The prediction of recurrence risk in all patients by using the mean of the independent six strongest genes $(P<1 \mathrm{E}-16$, $\mathrm{HR}=2.9, \mathrm{CI}=2.5-3.3$ ), of the four strongest genes in lymph node negative ER positive patients $(P<1 \mathrm{E}-16$, $\mathrm{HR}=2.8, \mathrm{CI}=2.2-3.5)$ and of the three genes in lymph node positive patients $(P=3.2 \mathrm{E}-9, \quad \mathrm{HR}=2.5, \quad \mathrm{CI}=$ 1.8-3.4) was highly significant. In summary, we integrated available knowledge in one platform to validate currently used predictors and to provide a global tool for the online determination of different prognostic parameters simultaneously using genome-wide microarrays.

Keywords Survival analysis - Breast cancer - Prognosis . Bioinformatics - Microarray - Recurrence score ·

Recurrence risk $\cdot$ Lymph node status

\section{Introduction}

Recently available multigenic prognostic biomarkers promise to provide a prediction efficiency superior to monogenic tests, enabling better patient tailored therapy in the treatment of breast cancer. In essence, development is carried out on two major platforms, including RT-PCRbased Oncotype DX [1], Theros Breast Cancer Index [2], Breast bioclassifier [3], Celera metastatic score [4], 8-gene score [5] and microarray-based Mammaprint [6], MapQuant Dx [7], BLN assay [8], Invasive Gene Signature [9] and Wound Response Indicator [10]. In addition, the FISHbased eXagen test [11] and the IHC-based Mammostrat 
Table 1 Summary of multigenic tests developed for breast cancer

\begin{tabular}{|c|c|c|c|c|c|c|}
\hline Name & Company & Available & $\begin{array}{l}\text { No of } \\
\text { genes }\end{array}$ & Sample & Technique & Diagnostic aim \\
\hline Oncotype Dx & Genomic Health & EU, USA & 21 & FFP & Q-RT-PCR & $\begin{array}{l}\text { Prognosis, recurrence after } \\
\text { tamoxifen therapy }\end{array}$ \\
\hline Theros Breast Cancer Index & Biotheranostics & USA & $2(5)$ & FFP & Q-RT-PCR & $\begin{array}{l}\text { Prognosis, recurrence after } \\
\text { endocrine therapy }\end{array}$ \\
\hline Breast Bioclassifier & ARUP & USA & 55 & FFP & RT-PCR & Prognosis \\
\hline Celera Metastatic Score & Applera & - & 14 & FFP & RT-PCR & $\begin{array}{l}\text { Prognosis, recurrence after } \\
\text { tamoxifen therapy }\end{array}$ \\
\hline eXagen & eXagen diagnostics & - & 3 & FFP & FISH & Prognosis \\
\hline Mammostrat & Applied genomics & USA & 5 & & $\mathrm{IHC}$ & Prognosis \\
\hline $\operatorname{ProEX}^{\mathrm{TM}} \mathrm{Br}$ & TriPath & - & 5 & & IHC & Prognosis \\
\hline MammaPrint & Agendia & EU, USA & 70 & $\mathrm{~F} / \mathrm{F}$ & Microarray & $\begin{array}{l}\text { Prognosis in patients over } \\
61 \text { years }\end{array}$ \\
\hline MapQuant Dx & Ipsoggen & EU & 97 & $\mathrm{~F} / \mathrm{F}$ & Microarray & Prognosis \\
\hline Breast Lymph Node (BLN) Assay & GeneSearch Veridex & UK & 76 & $\mathrm{~F} / \mathrm{F}$ & Microarray & $\begin{array}{l}\text { Intraoperative metastasis } \\
\text { identification }\end{array}$ \\
\hline Invasive Gene Signature & - & - & 186 & $\mathrm{~F} / \mathrm{F}$ & Microarray & Prognosis \\
\hline Wound Response Indicator & - & - & 512 & $\mathrm{~F} / \mathrm{F}$ & Microarray & Prognosis \\
\hline
\end{tabular}

F/F fresh/frozen, FFP formalin-fixed paraffin-embedded, IHC immunohistochemistry, FISH fish fluorescent in situ hybridization

[12] are available (see Table 1). Most of these datasets were summarized and evaluated in our recent meta-analysis [13].

Of the above mentioned tests, the Oncotype DX assay is by far the most widely used with over 135,000 tests performed already (Genomic Health Annual report, 2009). Here, FFPE samples are sent to a single laboratory, where the isolation of RNA and analysis are performed. Twentyone genes are quantified in the test to predict distant recurrence in breast cancer patients with lymph-node negative, estrogen-receptor (ER) positive tumors. Patients are classified into high/intermediate/low risk of recurrence based on the recurrence score, which is computed using an precisely defined mathematical formula [1]. The assay not only provides prediction of relapse-free survival, but also predicts the risk of locoregional recurrence [14]. It might also support the treatment decision whether a patient should receive adjuvant chemotherapy [15]. The benefit of adjuvant chemotherapy over and above endocrine therapy differs greatly in the assay-determined risk categories [16]. The effect of Oncotype Dx on physicians' decision-making for systemic adjuvant therapy ranged from $25 \%$ [17] to $44 \%$ [18]. The actual cost of the assay itself seems to be well justified by saving the cost of unnecessary chemotherapy [19]. However, significant weaknesses of the test are the lack of any independent quality control and the slow processing requiring several weeks.

Determining estrogen receptor status accurately is essential to identify patients eligible for endocrine therapy in breast cancer. Another receptor of significant clinical importance is HER2 (ERBB2), which is over-expressed in over $25 \%$ of invasive ductal breast cancers [20]. The elevated levels of HER2 are associated with increased proliferation and poor prognosis [21]. Immunhistochemistry based HER2 positive patients are eligible for first-line trastuzumab treatment in combination with chemotherapy [22] and for monotherapy in patients who progressed after chemotherapy [23]. Trastuzumab treatment results in increased response rate and longer survival [22].

A genome-wide Affymetrix microarray measures over 22,000 genes including the hormone receptors and those genes used in different multigenic breast cancer classifications. Here, we report the development of an online analysis tool which is capable of computing ER and HER2 status and the risk of recurrence using gene expression data obtained by interrogating Affymetrix HGU133A and HGU133Aplus2 microarrays. Furthermore, we implemented rigorous quality control algorithms to promptly exclude any biases related to sample processing, hybridization and scanning. We performed a validation of the system in 2,472 breast cancer specimens obtained from microarray datasets published in GEO.

\section{Methods}

\section{Server set-up}

All computations on the raw microarray data are performed in real time (Fig. 1). Recurrence online is set up using a 
Fig. 1 Overview of the server (a), the eligible tests (b), the applied analysis corridor in the online computations (c) and the implementation of the validation study (d)

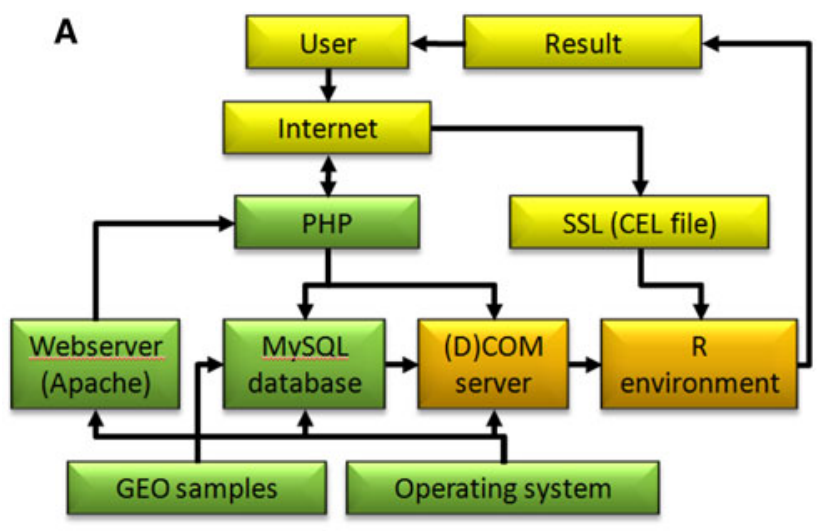

B

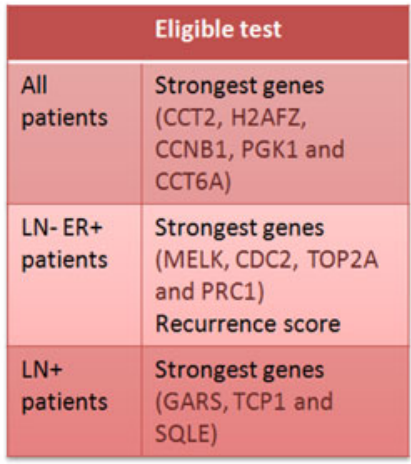

C

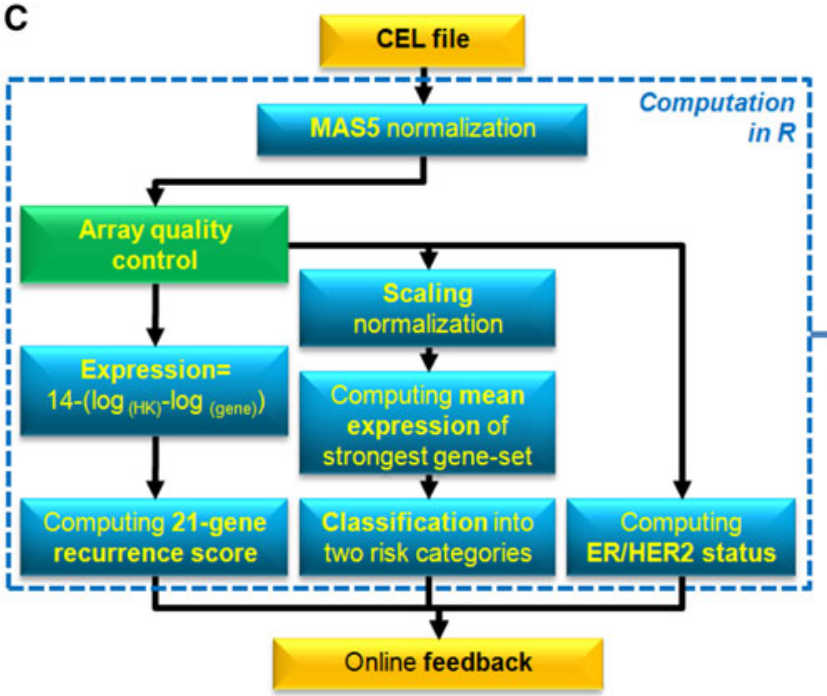

D

Breast cancer samples in GEO $(n=2,472)$

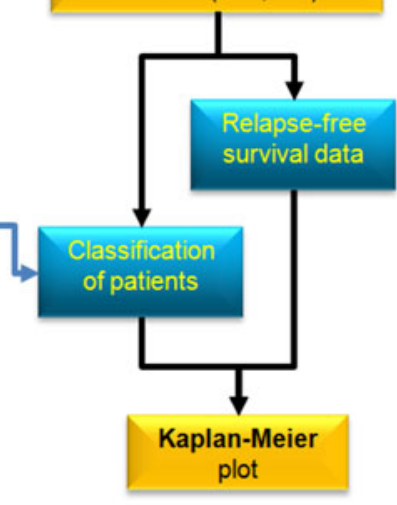

central server accessible via the internet. The central server runs an Apache webserver and a (D)COM server which provides statistical computations in $\mathrm{R}$. After a secure upload of the .CEL file, data is loaded into the $\mathrm{R}$ statistical environment, where the calculations are performed. The package "affy" is used for normalization. For the validation, the background database is handled by a MySQL server, which integrates gene expression and clinical data simultaneously. The homepage was constructed using a modular online system built in the freely available drupal ( www.drupal.org) environment. The user receives feedback from the webpage.

We focused on the two most widely used human microarray platforms, the Affymetrix HGU133A (GEO platform ID: GPL96) and the Affymetrix HGU133plus2 (GEO platform ID: GPL570). The final output of a hybridization of an Affymetrix microarray is the acquisition of a .CEL file, which contains all the raw results of the microarray. The implemented various metrics of our tool rely on these raw .CEL files. The input window of recurrenceonline.com is presented in Fig. 2a.
Array quality control

Heber and Sick [24] suggested eight quality metrics as a basic quality assessment for Affymetrix microarrays. First, we have implemented their methods and tested them on an extended version of our previously published database [25]. The distribution of the arrays was assessed and outliers were identified as those having a parameter value outside of the range of $95 \%$ of samples. Then, the "Array quality control" parameter implemented in www.recurrenceonline.com was set to give a warning in cases in which the thresholds published by Heber et al. are surpassed or outliers are detected as compared to our meta-analysis. The cutoff values are summarized in Table 2 .

\section{Computation of the recurrence score}

After the quality control the raw Affymetrix .CEL files are MAS5 normalized in $R$ using the affy Bioconductor library. MAS5 can be applied to individual chips, making comparison to the validation data and future extension of the 
Fig. 2 a One-step online interface is used for input (a). The analysis results window b delivers a graphical assessment of the tested parameters
A

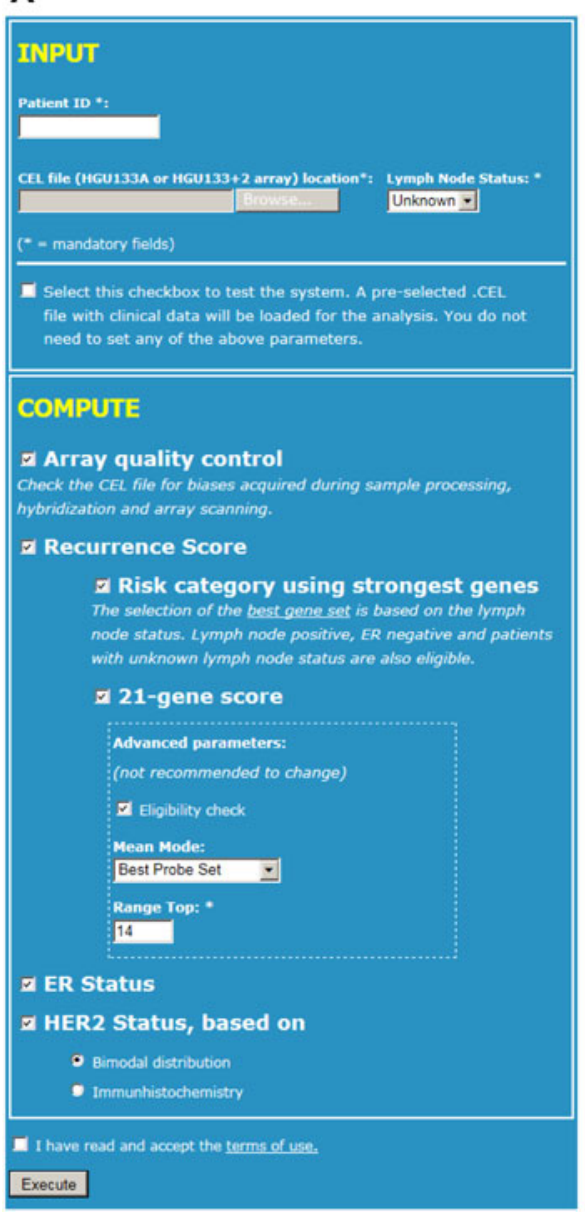

B

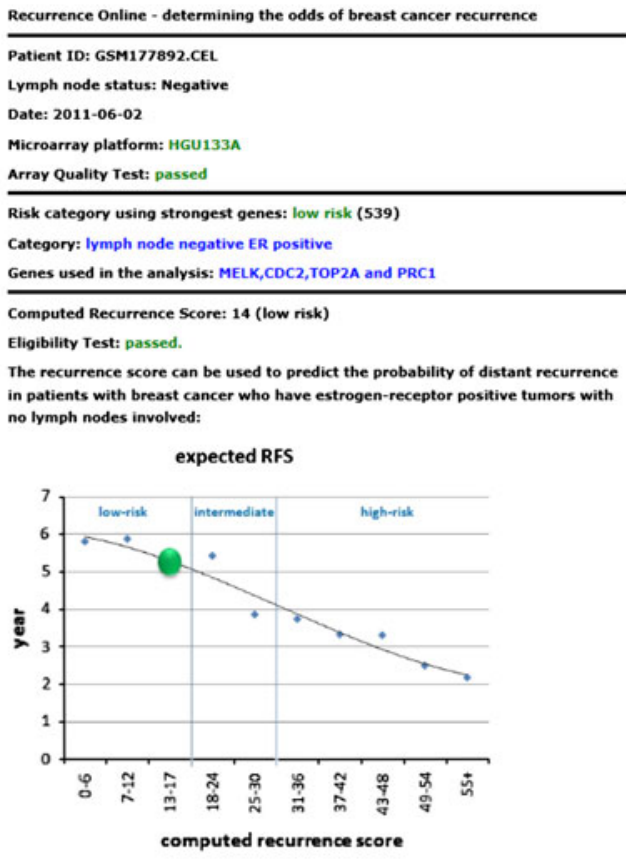

ER status: Positive. (MASS normalized gene expression: 8090) $\mathrm{x}$

ER negative
HER2 Status: Negative. (MASS normalized gene expression: 1266)

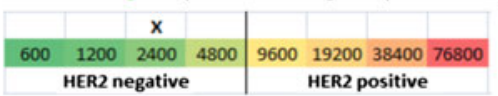

Table 2 Parameters implemented in the array quality control metrics

\begin{tabular}{llll}
\hline Parameter & $\begin{array}{l}\text { Recommendation by Heber et al. } \\
\text { for good quality arrays }\end{array}$ & $\begin{array}{l}\text { Range of 95\% of arrays in 2,472 } \\
\text { breast cancer samples }\end{array}$ & $\begin{array}{l}\text { www.recurrenceonline.com } \\
\text { gives warning if result is }\end{array}$ \\
\hline Background & Between 10 and 100 normal & $40-114$ & Larger than 100 \\
Scaling factor & Smaller than 3 & $0.3-2.3$ & Larger than 3 \\
Percent present calls & In the range 20-50\% & $42-58 \%$ & Smaller than 30\% \\
bioB-, bioC-, bioD- and cre-spikes & Always present & Not applicable & Not present \\
dap-, lys-, phe-, thr-, tryp-spikes & lys $<$ phe $<$ thr $<$ dap & Not applicable & Not "lys $<$ phe $<$ thr $<$ dap" \\
GAPDH 3' to 5' ratio & Close to one & $0.28-5$ & Larger than 4 or smaller than 0.25 \\
Beta-actin 3' to 5' ratio & Smaller than 3 & $0-4.7$ & Larger than 3 \\
\hline
\end{tabular}

validation datasets easily feasible. Moreover, MAS5 ranked among the best normalization methods when compared to the results of RT-PCR measurements in our recent study [26]. Then, the differences of the log-transformed expression of the 16 genes and the housekeeping genes ACTB, GAPDH, RPLP0, GUS, and TFRC are subtracted from the "range top" (adjustable parameter) to emulate RT-PCR results. For genes with multiple probe sets represented on the Affymetrix microarrays the probe set with the highest average expression or the average expression of available probe sets can be used (adjustable parameter). Then, the recurrence score is computed as described by Paik et al. 2004. Finally, samples are classified as being in the high/ intermediate/low group based on their recurrence score.

\section{Assessment of ER and HER2 status}

Gong et al. [27] demonstrated the possibility to determine estrogen receptor and ERBB2 status reliably and reproducibly using Affymetrix microarrays. We implemented their 
approach using the suggested cutoff values of 500 (in the probe set 205225_at) for estrogen receptor and 1,150 (in the probe set 216836_s_at) for ERBB2 receptor. In addition, for the ERBB2 receptor the bimodal distribution of the validation datasets was decomposed into two Gaussian distributions (which correspond to two specific ERBB2 expression statuses) as described earlier [28]. Briefly, based on the two inferred distributions a cohort-specific cut-off value for ERBB2 using Mahalanobis distance-which minimizes the estimated false positive rate (FPR) and the false negative rate (FNR) - was derived. The actual cutoff for ERBB2 is user selectable: "bimodal distribution" uses 4,800 as cutoff, while "immunhistochemistry" uses the 1,150 cutoff suggested by Gong et al.

\section{Validation}

The validation was performed on microarrays which were previously published in GEO in following datasets: GSE1456, GSE2034, GSE2990, GSE3494, GSE4922, GSE6532, GSE7390, GSE11121, GSE12093, GSE5327, GSE9195, GSE16391, GSE12276, GSE2603, GSE17705, and GSE21653. The datasets were generated using HGU133A or HGU133Aplus2 microarrays which possess overlapping probe set identifiers and are also used in www.recurrenceonline.com analyses. The construction of the database was performed as described earlier [25]. After classification of the samples as having high/intermediate/ low recurrence scores, the groups were compared using Kaplan-Meier survival plots in WinSTAT 2007 for Excel (Robert K. Fitch Software, Germany) and using the "survplot" package (http://www.cbs.dtu.dk/ eklund/survplot/) in $\mathrm{R}$.

Computation of risk category using the "strongest genes"

Using our validation database we identified the genes with the strongest predictive power in all patients, in lymph node positive, and in lymph node negative ER positive and ER negative patients. First, a filtering was performed to select only those probe sets which reliably work on the microarray. Probe sets were retained having a median expression over 890 (the whole-array median) or having a median expression of at least 445 and covering at least $20 \%$ of the gene and not mapping to multiple genes. After this, the gene with the lowest $p$ value and the highest HR value in the given cohort of patients was selected. Then, the second probe set was added, and the mean expression of the two probe sets was used for classification. This was repeated as long as the predictive power of the mean of the used probe sets increased. A leave-one-out cross validation (LOOCV) was performed in each of the three cohorts to measure the robustness as whether the same genes will be selected by excluding any of the samples. Finally, the classification was implemented in RecurrenceOnline as the "Risk category using strongest genes" option.

Comparison of classification performance by using ROC

Although we do not had access to the Oncotype DX scores for the same samples, we contrasted area under the curve (AUC) measures using our methods and published AUC measures available for the Oncotype DX [29]. ROC analysis was performed using MedCalc 11.6. (MedCalc Software, Mariakerke, Belgium).

\section{Results}

\section{Online system}

We have established an online platform which enables the computation of four different features using Affymetrix HGU133A or HGU133plus2 microarray data. An example of a complete analysis is depicted in Fig. 2b.

On these microarrays, some genes are measured by several probe sets. For the analysis of ERBB2 status and ER status, we used the probe sets with the highest average expression. For the prediction of the recurrence score, one can decide how to handle these probe sets for each gene. The "Average" computes the average expression of all available probe sets for each gene. The "Best probe set" uses only the best probe as measured by average expression of each probe set and mapping to the gene by blasting to Ensembl genes. Finally, as one of the housekeeping genes is related to proliferation (GAPDH) [30], this gene can be excluded from the analysis using the "Best probe-GAPDH" option.

The ER and ERBB2 status are computed using the MAS5 normalized expression values. The computation of the recurrence score is preceded by a transformation of the linear MAS5 expression values to logarithmic scale. In contrast to RT-PCR, where larger values mean lower expression, larger values mean higher expression on microarrays. Therefore, an inversion is necessary, and the range top parameter defines in this context the top of the dynamic range on the microarray.

Validation cohort

All together 2,472 microarray measurements were entered into the validation database. The average relapse-free survival is $6.39 \pm 4.0$ years with $869 / 2,239$ relapses. Only lymph node negative patients with available relapse-free survival times $(n=1,509)$ were included in the basic classification 

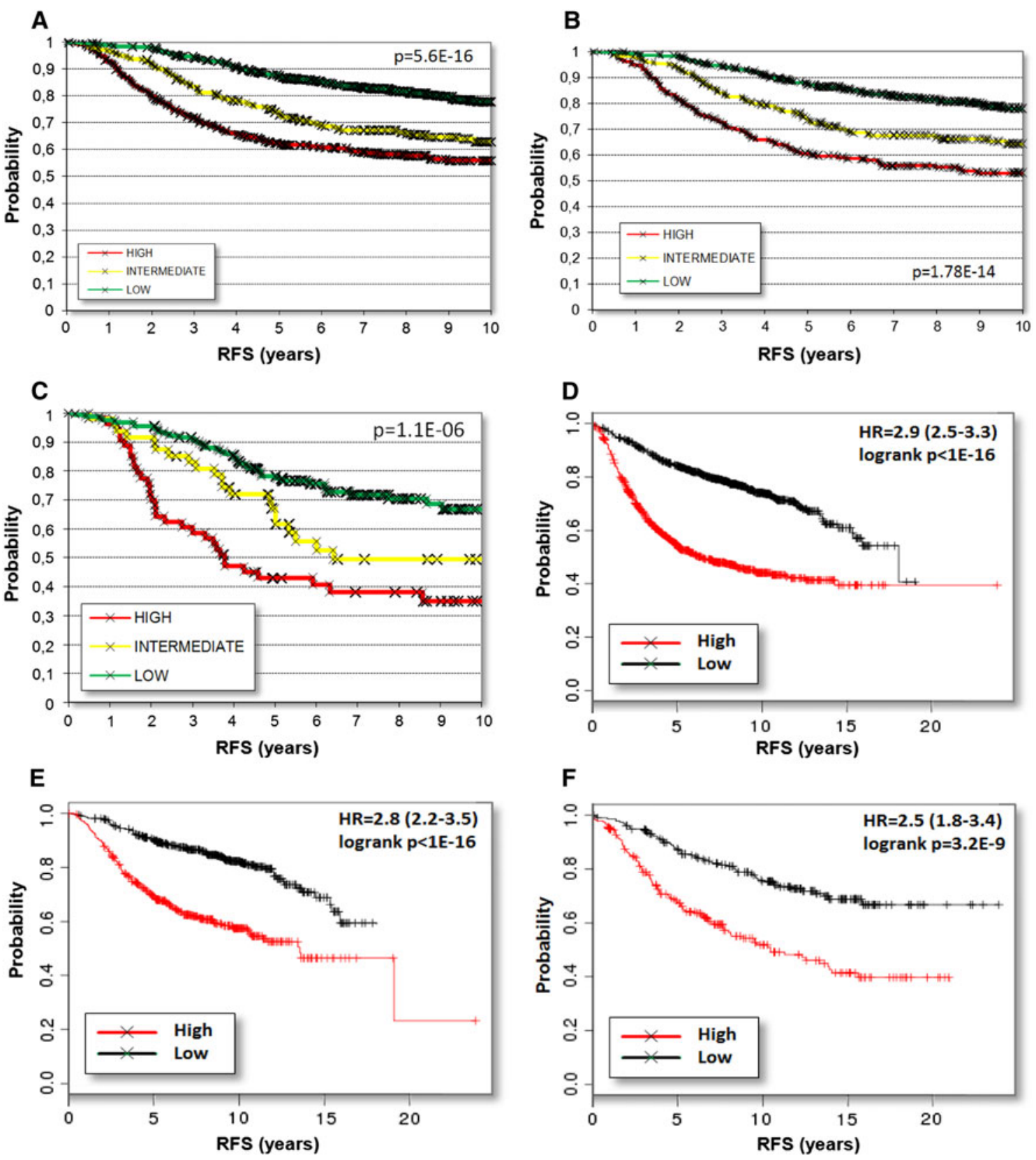

Fig. 3 Kaplan-Meier plots of survival based on classification using the recurrence score in all lymph node negative patients $(n=1,509)$ (a), and in lymph node negative estrogen receptor positive patients (b, $n=1,028$, ER status is IHC based). The recurrencescore-classification is also effective in only tamoxifen treated (d, $n=251$ ) estrogen receptor positive, lymph node negative

patients. Classification using the mean expression of the six independent strongest genes in all patients regardless of lymph node and ER status (d, $n=2,316)$, the strongest four genes in lymph node negative ER positive patients (e, $n=1,077$, ER status is array-based); and the strongest three genes in lymph node positive patients $(\mathbf{f}, n=482)$

using the recurrence score algorithm. The classification resulted in $46 \%(n=701)$ of patients classified into the low, $19 \%(n=279)$ into the intermediate and $35 \%(n=527)$ into the high-risk group, the Kaplan-Meier plots for all three categories are depicted in Fig. 3a. In these patients, the difference in the survival curves were significant $(P=5.6 \mathrm{E}-$ 16 , Hazard Ratio $=0.40$, Confidence Interval $=0.32-0.50$ ). The significance was slightly reduced when only ER positive

samples were included for the recurrence score $(P=2.1 \mathrm{E}-$ $15, \mathrm{HR}=0.36, \mathrm{CI}=0.28-0.47$ (see Fig. 3b). The classification of the 1,509 lymph node negative patients using the available clinical variables resulted in much lower significances (ER status: $P=0.0002, \mathrm{HR}=0.66, \mathrm{CI}=0.51-0.86$, grade: $P=$ not significant). In many previous publications, authors reported not only the overall significance, but also the significance between the worst and the best performing 


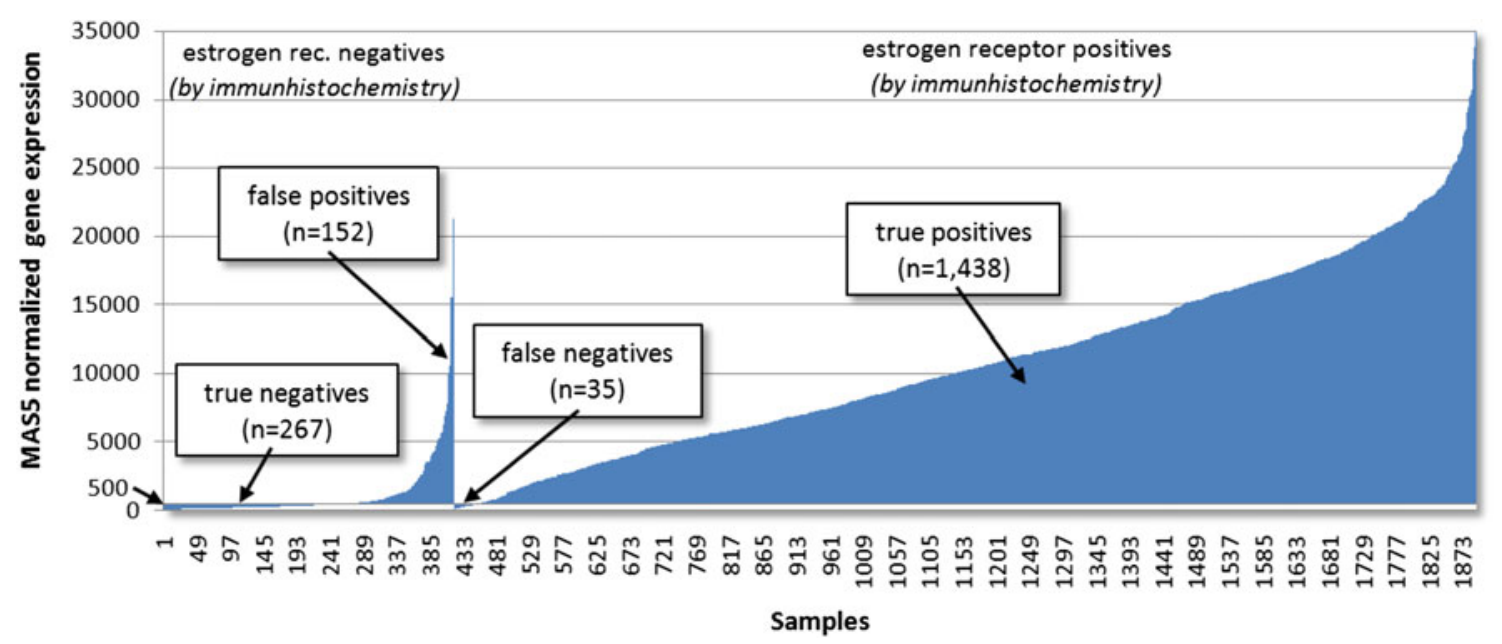

Fig. 4 Validation of the estrogen receptor status determination in 1,894 patients with available immunhistochemistry results. The patients are ordered on the basis of the expression of the probe set 205225_at, which corresponds to the ESR1 gene. The horizontal axis crosses the vertical axis at 500, which is used as a threshold for determining the estrogen receptor state as positive or negative. By using this threshold, over $90 \%$ of patients are correctly classified

for classification $(n=482$; cutoff $=2600, P=3.2 \mathrm{E}-9$, $\mathrm{HR}=2.5, \mathrm{CI}=1.8-3.4$, see Fig. 3f).

In the leave-one-out cross validation of the cohort containing "all patients", and of the "lymph node negative ER positive patients" the set of the top genes was confirmed in $100 \%$ of the analyses. In the "lymph node positive" cohort, the selected genes were confirmed in $91.9 \%$ of the analyses. One gene, GATAD2A, surpassed SQLE in $8.1 \%$ of the LOOCV tests. However, addition of GATAD2A did not increase predictive power $(P=1 \mathrm{E}-8$, $\mathrm{HR}=2.4, \mathrm{CI}=1.8-3.3$.$) .$

\section{Validation of ER-status determination}

Estrogen receptor status based on immunohistochemical assessment (IHC) was available for 1,894 patients. Of these, 267 were classified as negative and 1,438 as positive by both IHC and microarray. Positive IHC with negative microarray results were obtained in 35 samples and positive microarray with negative IHC results in 152 patients. In summary, $88.5 \%$ of ER - and $90.5 \%$ of ER+ samples were classified correctly (see Fig. 4).

Another important feature of the ER status is the fact, that only ER positive patients are eligible for the original recurrence score analysis. Therefore, we used our ER-status determination and computed the recurrence score separately (in lymph node negative patients with available survival) for patients having positive IHC results $(n=1,028)$ and for patients having positive microarray results $(n=1,090)$. While the Kaplan-Meier survival plots delivered a significant difference in both cases, the group having the array-based ER-status determination had a stronger predictive power 
$(P=2.1 \mathrm{E}-15, \mathrm{HR}=0.36, \mathrm{CI}=0.28-0.47$ vs. $P<1 \mathrm{E}-$ $16, \mathrm{HR}=0.36, \mathrm{CI}=0.28-0.46)$.

\section{Comparison of classification performances}

The AUC for the mean of strongest genes in all patients was 0.695 (sensitivity $=63 \%$, specificity $=67 \%$ ). For the strongest genes in the lymph node negative ER positive patients the AUC was 0.613 (sensitivity $=67 \%$, specificity $=56 \%$ ), and for the mean of the strongest genes of lymph node positive patients the AUC was 0.569 (sensitivity $=45 \%$, specificity $=69 \%$ ).

The AUC of RecurrenceOnline in the ROC analysis using the 21-gene score for all lymph node negative and ER positive patients was 0.637 (sensitivity $=61 \%$, specificity $=62 \%)$. The previous AUC for Oncotype DX was 0.59 (sensitivity $=68 \%$, specificity $=50 \%$ ) [29].

The AUC for the estrogen status determination in the ROC analysis was 0.807 (sensitivity $=97 \%$, specificity $=64 \%$ ). The ROC plots are depicted on Fig. 5 .

\section{Array quality control}

All together 77 samples (out of 2,472) failed at least one of the quality control thresholds, 7 samples failed more than one quality parameter. Of the first, 46 were lymph node negative and of these, 39 were ER positive. Discrimination of these patients by Kaplan-Meier survival analysis using the computed RS score was impossible $(P=0.11)$.

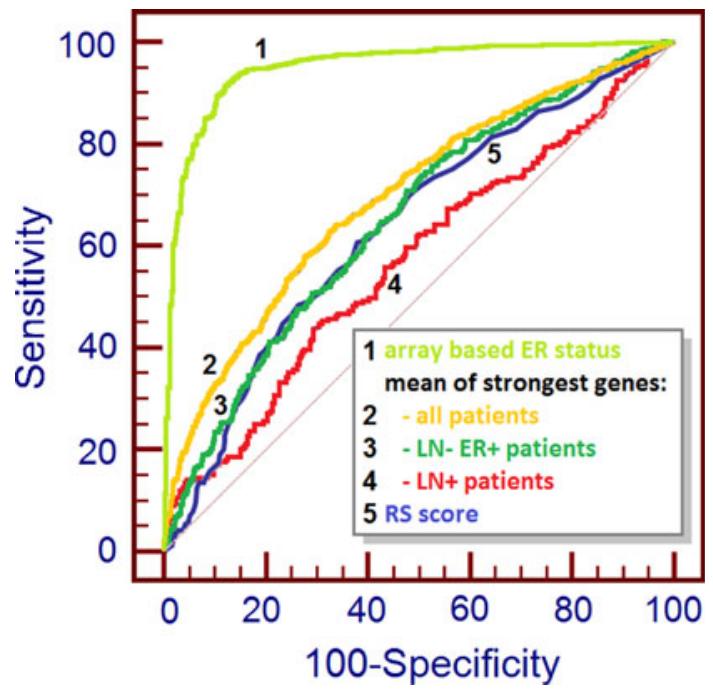

Fig. 5 ROC plots for the implemented risk category prediction sets: the array-based ER status determination vs. IHC based actual ER status (1), the predictive power of the strongest genes identified in all patients (2), LN-ER+ patients (3), LN+ patients (4) and the predictive power of the recurrence-online computed recurrence score (5)

\section{Discussion}

In our study, we aimed to prepare a tool capable to perform different assays simultaneously by the use of genome-wide microarrays. The approach is based on the fact that microarray facilities are available at virtually all university research centers. Thus, the microarray profiles of individual tumor specimens obtained at these centers can be compared to and evaluated in the context of a large number of clinical cases, which have been carefully characterized in previous publications and, hence, can be considered as a global reference. This can be performed in a shared resource setting by www.recurrenceonline.com.

We successfully validated recurrenceonline.com using 2,472 independent gene expression profiles of breast cancer specimens, available in GEO with clinical follow-up. The predictive power of our study is higher as compared to the original classifications [1]. Most probably there are several reasons for this improvement: RNA is prepared from fresh material prior to microarray analysis. This procedure allows improves expression measurements compared to paraffin embedded tissue as the source of RNA. The second reason is the use of multiple probe sets for the measurement of the genes on the microarrays. This enables us to select the best probe sets which in turn will enable higher prediction accuracy. Finally, we used a much larger set of patients for validation than previous studies in combination. Unfortunately, direct comparison of recurrence online with Oncotype Dx using tumour samples was not possible as we do not had access to samples for which both Oncotype Dx assay and Affymetrix microarrays have been performed.

We also show the capability to classify the patients regardless of lymph node and ER status into high-risk and low-risk cohorts using three independent sets of predictive genes. As today all lymph node positive patients routinely receive chemotherapy, a more in-depth analysis of these patients will be needed for estimation of treatment consequences.

The determination of ER status relies on a study of Gong et al [27], who effectively used microarrays for ER and HER2 receptor status determination. We implemented their system, but had only enough data to validate the ER-status prediction. The prediction achieved a very high success rate of $\sim 90 \%$. In addition, the measurement of the ER status by microarray further improved the recurrence score designed only for ER positive patients. For the HER2 determination, we also implemented a cut-off value based on the expected bimodal distribution of the receptor expression values as published by Li et al [28].

One might consider quality issues related to the use of microarrays for the measurement of gene expression. Reproducibility of the gene expression measurements was 
already confirmed by the MAQC consortia [31]. However, the high data volume and data complexity in microarray experiments carry many potential sources of unwanted variation that could compromise the results if left uncontrolled. This growing concern and awareness of the importance of assessing the quality of generated microarray data was assessed in a review published by Heber and Sick [24]. Therefore, we implemented a quality metrics measurement based on their suggested parameters. Particularly, seven different quality parameters related to biases in sample processing, hybridization and scanning are assessed by www.recurrenceonline.com. The value of this added analysis is outlined by the fact, that the classification of the samples with failed quality control was not successful. We have set up the system to leave the decision to the investigator, and the report gives a warning in case that the quality of the microarray used is low.

Besides the validation of proprietary analysis pipelines, our system can accelerate prognosis prediction by enabling rapid evaluation of locally processed samples. Theoretically, the local diagnostic pathway can be completed in $\sim 24 \mathrm{~h}$, thereby reducing the time currently needed for such an analysis by over $95 \%$. The computational analysis itself is completed in less than $10 \mathrm{~min}$. The speed could bring additional benefits for the patients, who could receive the most appropriate treatment within a shorter time.

In summary, we developed an online classification system capable of using common genome-wide microarrays to assess hormone receptor status and to compute the risk of recurrence. The system performs all bioinformatic steps automatically and is therefore also suitable for users with negligible statistical knowledge. As the present scheme can be extended with additional gene sets and be applied to other cancer types, one might envision a future single step approach, which permits diagnosis of different tumor types in the same automated pipeline.

Acknowledgements BG was supported by the Alexander von Humboldt Stiftung.

Disclosure None

\section{References}

1. Paik S, Shak S, Tang G, Kim C, Baker J, Cronin M, Baehner FL, Walker MG, Watson D, Park T, Hiller W, Fisher ER, Wickerham DL, Bryant J, Wolmark N (2004) A multigene assay to predict recurrence of tamoxifen-treated, node-negative breast cancer. N Engl J Med 351(27):2817-2826. doi:10.1056/NEJMoa041588

2. Ma XJ, Salunga R, Dahiya S, Wang W, Carney E, Durbecq V, Harris A, Goss P, Sotiriou C, Erlander M, Sgroi D (2008) A fivegene molecular grade index and HOXB13:IL17BR are complementary prognostic factors in early stage breast cancer. Clin Cancer Res 14(9):2601-2608. doi:10.1158/1078-0432.CCR-07-5026
3. Parker JS, Mullins M, Cheang MC, Leung S, Voduc D, Vickery T, Davies S, Fauron C, He X, Hu Z, Quackenbush JF, Stijleman IJ, Palazzo J, Marron JS, Nobel AB, Mardis E, Nielsen TO, Ellis MJ, Perou CM, Bernard PS (2009) Supervised risk predictor of breast cancer based on intrinsic subtypes. J Clin Oncol 27(8):1160-1167. doi:10.1200/JCO.2008.18.1370

4. Tutt A, Wang A, Rowland C, Gillett C, Lau K, Chew K, Dai H, Kwok S, Ryder K, Shu H, Springall R, Cane P, McCallie B, KamMorgan L, Anderson S, Buerger H, Gray J, Bennington J, Esserman L, Hastie T, Broder S, Sninsky J, Brandt B, Waldman F (2008) Risk estimation of distant metastasis in node-negative, estrogen receptor-positive breast cancer patients using an RTPCR based prognostic expression signature. BMC Cancer 8:339. doi:10.1186/1471-2407-8-339

5. Sanchez-Navarro I, Gamez-Pozo A, Pinto A, Hardisson D, Madero R, Lopez R, San Jose B, Zamora P, Redondo A, Feliu J, Cejas P, Gonzalez Baron M, Angel Fresno Vara J, Espinosa E (2010) An 8-gene qRT-PCR-based gene expression score that has prognostic value in early breast cancer. BMC Cancer 10:336. doi: 10.1186/1471-2407-10-336

6. van de Vijver MJ, He YD, van't Veer LJ, Dai H, Hart AA, Voskuil DW, Schreiber GJ, Peterse JL, Roberts C, Marton MJ, Parrish M, Atsma D, Witteveen A, Glas A, Delahaye L, van der Velde T, Bartelink H, Rodenhuis S, Rutgers ET, Friend SH, Bernards R (2002) A gene-expression signature as a predictor of survival in breast cancer. N Engl J Med 347(25):1999-2009. doi: 10.1056/NEJMoa021967

7. Sotiriou C, Wirapati P, Loi S, Harris A, Fox S, Smeds J, Nordgren H, Farmer P, Praz V, Haibe-Kains B, Desmedt C, Larsimont D, Cardoso F, Peterse H, Nuyten D, Buyse M, Van de Vijver MJ, Bergh J, Piccart M, Delorenzi M (2006) Gene expression profiling in breast cancer: understanding the molecular basis of histologic grade to improve prognosis. J Natl Cancer Inst 98(4):262-272. doi:10.1093/jnci/djj052

8. Mansel RE, Goyal A, Douglas-Jones A, Woods V, Goyal S, Monypenny I, Sweetland H, Newcombe RG, Jasani B (2009) Detection of breast cancer metastasis in sentinel lymph nodes using intra-operative real time GeneSearch BLN Assay in the operating room: results of the Cardiff study. Breast Cancer Res Treat 115(3):595-600. doi:10.1007/s10549-008-0155-6

9. Liu R, Wang X, Chen GY, Dalerba P, Gurney A, Hoey T, Sherlock G, Lewicki J, Shedden K, Clarke MF (2007) The prognostic role of a gene signature from tumorigenic breast-cancer cells. N Engl J Med 356(3):217-226. doi:10.1056/NEJMoa063994

10. Chang HY, Sneddon JB, Alizadeh AA, Sood R, West RB, Montgomery K, Chi JT, van de Rijn M, Botstein D, Brown PO (2004) Gene expression signature of fibroblast serum response predicts human cancer progression: similarities between tumors and wounds. PLoS Biol 2(2):E7. doi:10.1371/journal.pbio.0020007

11. Davis LM, Harris C, Tang L, Doherty P, Hraber P, Sakai Y, Bocklage T, Doeden K, Hall B, Alsobrook J, Rabinowitz I, Williams TM, Hozier J (2007) Amplification patterns of three genomic regions predict distant recurrence in breast carcinoma. J Mol Diagn 9(3):327-336

12. Ring BZ, Seitz RS, Beck R, Shasteen WJ, Tarr SM, Cheang MC, Yoder BJ, Budd GT, Nielsen TO, Hicks DG, Estopinal NC, Ross DT (2006) Novel prognostic immunohistochemical biomarker panel for estrogen receptor-positive breast cancer. J Clin Oncol 24(19):3039-3047. doi:10.1200/JCO.2006.05.6564

13. Gyorffy B, Schafer R (2009) Meta-analysis of gene expression profiles related to relapse-free survival in 1,079 breast cancer patients. Breast Cancer Res Treat 118(3):433-441. doi: 10.1007/s10549-008-0242-8

14. Mamounas EP, Tang G, Fisher B, Paik S, Shak S, Costantino JP, Watson D, Geyer CE Jr, Wickerham DL, Wolmark N (2010) Association between the 21-gene recurrence score assay and risk of 
locoregional recurrence in node-negative, estrogen receptor-positive breast cancer: results from NSABP B-14 and NSABP B-20. J Clin Oncol 28(10):1677-1683. doi:10.1200/JCO.2009.23.7610

15. Paik S, Tang G, Shak S, Kim C, Baker J, Kim W, Cronin M, Baehner FL, Watson D, Bryant J, Costantino JP, Geyer CE Jr, Wickerham DL, Wolmark N (2006) Gene expression and benefit of chemotherapy in women with node-negative, estrogen receptor-positive breast cancer. J Clin Oncol 24(23):3726-3734. doi: 10.1200/JCO.2005.04.7985

16. Albain KS, Paik S, van't Veer L (2009) Prediction of adjuvant chemotherapy benefit in endocrine responsive, early breast cancer using multigene assays. Breast 18(Suppl 3):S141-S145. doi:10.1016/ S0960-9776(09)70290-5

17. Oratz R, Paul D, Cohn AL, Sedlacek SM (2007) Impact of a commercial reference laboratory test recurrence score on decision making in early-stage breast cancer. J Oncol Pract 3(4):182-186. doi:10.1200/JOP.0742001

18. Asad J, Jacobson AF, Estabrook A, Smith SR, Boolbol SK, Feldman SM, Osborne MP, Boachie-Adjei K, Twardzik W, Tartter PI (2008) Does oncotype DX recurrence score affect the management of patients with early-stage breast cancer? Am J Surg 196(4):527-529. doi:10.1016/j.amjsurg.2008.06.021

19. Lyman GH, Cosler LE, Kuderer NM, Hornberger J (2007) Impact of a 21-gene RT-PCR assay on treatment decisions in early-stage breast cancer: an economic analysis based on prognostic and predictive validation studies. Cancer 109(6):1011-1018. doi:10.1002/ cncr.22506

20. Press MF, Hung G, Godolphin W, Slamon DJ (1994) Sensitivity of HER-2/neu antibodies in archival tissue samples: potential source of error in immunohistochemical studies of oncogene expression. Cancer Res 54(10):2771-2777

21. Slamon DJ, Clark GM, Wong SG, Levin WJ, Ullrich A, McGuire WL (1987) Human breast cancer: correlation of relapse and survival with amplification of the HER-2/neu oncogene. Science 235(4785): 177-182

22. Slamon DJ, Leyland-Jones B, Shak S, Fuchs H, Paton V, Bajamonde A, Fleming T, Eiermann W, Wolter J, Pegram M, Baselga J, Norton L (2001) Use of chemotherapy plus a monoclonal antibody against HER 2 for metastatic breast cancer that overexpresses HER2. N Engl J Med 344(11):783-792. doi:10.1056/NEJM200103153441101

23. Cobleigh MA, Vogel CL, Tripathy D, Robert NJ, Scholl S, Fehrenbacher L, Wolter JM, Paton V, Shak S, Lieberman G, Slamon DJ (1999) Multinational study of the efficacy and safety of humanized anti-HER2 monoclonal antibody in women who have HER2-overexpressing metastatic breast cancer that has progressed after chemotherapy for metastatic disease. J Clin Oncol 17(9):2639-2648

24. Heber S, Sick B (2006) Quality assessment of Affymetrix GeneChip data. OMICS 10(3):358-368. doi:10.1089/omi.2006.10.358

25. Gyorffy B, Lanczky A, Eklund AC, Denkert C, Budczies J, Li Q, Szallasi Z (2009) An online survival analysis tool to rapidly assess the effect of 22,277 genes on breast cancer prognosis using microarray data of 1,809 patients. Breast Cancer Res Treat. doi: 10.1007/s10549-009-0674-9
26. Gyorffy B, Molnar B, Lage H, Szallasi Z, Eklund AC (2009) Evaluation of microarray preprocessing algorithms based on concordance with RT-PCR in clinical samples. PLoS One 4(5):e5645. doi:10.1371/journal.pone.0005645

27. Gong Y, Yan K, Lin F, Anderson K, Sotiriou C, Andre F, Holmes FA, Valero V, Booser D, Pippen JE Jr, Vukelja S, Gomez H, Mejia J, Barajas LJ, Hess KR, Sneige N, Hortobagyi GN, Pusztai L, Symmans WF (2007) Determination of oestrogen-receptor status and ERBB2 status of breast carcinoma: a gene-expression profiling study. Lancet Oncol 8(3):203-211. doi:10.1016/S1470-2045(07) 70042-6

28. Li Q, Eklund AC, Juul N, Haibe-Kains B, Workman CT, Richardson AL, Szallasi Z, Swanton C (2010) Minimising immunohistochemical false negative er classification using a complementary 23 gene expression signature of ER status. PLoS One 5(12):e15031. doi: 10.1371/journal.pone.0015031

29. Li LF, Xu XJ, Zhao Y, Liu ZB, Shen ZZ, Jin WR, Shao ZM (2009) Integrated gene expression profile predicts prognosis of breast cancer patients. Breast Cancer Res Treat 113(2):231-237. doi:10.1007/s10549-008-9925-4

30. Beroukhim R, Brunet JP, Di Napoli A, Mertz KD, Seeley A, Pires MM, Linhart D, Worrell RA, Moch H, Rubin MA, Sellers WR, Meyerson M, Linehan WM, Kaelin WG Jr, Signoretti S (2009) Patterns of gene expression and copy-number alterations in vonHippel Lindau disease-associated and sporadic clear cell carcinoma of the kidney. Cancer Res 69(11):4674-4681. doi:10.1158/00085472.CAN-09-0146

31. Shi L, Reid LH, Jones WD, Shippy R, Warrington JA, Baker SC, Collins PJ, de Longueville F, Kawasaki ES, Lee KY, Luo Y, Sun YA, Willey JC, Setterquist RA, Fischer GM, Tong W, Dragan YP, Dix DJ, Frueh FW, Goodsaid FM, Herman D, Jensen RV, Johnson CD, Lobenhofer EK, Puri RK, Schrf U, Thierry-Mieg J, Wang C, Wilson M, Wolber PK, Zhang L, Amur S, Bao W, Barbacioru CC, Lucas AB, Bertholet V, Boysen C, Bromley B, Brown D, Brunner A, Canales R, Cao XM, Cebula TA, Chen JJ, Cheng J, Chu TM, Chudin E, Corson J, Corton JC, Croner LJ, Davies C, Davison TS, Delenstarr G, Deng X, Dorris D, Eklund AC, Fan XH, Fang H, Fulmer-Smentek S, Fuscoe JC, Gallagher K, Ge W, Guo L, Guo X, Hager J, Haje PK, Han J, Han T, Harbottle HC, Harris SC, Hatchwell E, Hauser CA, Hester S, Hong H, Hurban P, Jackson SA, Ji H, Knight CR, Kuo WP, LeClerc JE, Levy S, Li QZ, Liu C, Liu Y, Lombardi MJ, Ma Y, Magnuson SR, Maqsodi B, McDaniel T, Mei N, Myklebost O, Ning B, Novoradovskaya N, Orr MS, Osborn TW, Papallo A, Patterson TA, Perkins RG, Peters EH, Peterson R, Philips KL, Pine PS, Pusztai L, Qian F, Ren H, Rosen M, Rosenzweig BA, Samaha RR, Schena M, Schroth GP, Shchegrova S, Smith DD, Staedtler F, Su Z, Sun H, Szallasi Z, Tezak Z, Thierry-Mieg D, Thompson KL, Tikhonova I, Turpaz Y, Vallanat B, Van C, Walker SJ, Wang SJ, Wang Y, Wolfinger R, Wong A, Wu J, Xiao C, Xie Q, Xu J, Yang W, Zhong S, Zong Y, Slikker W Jr. (2006) The MicroArray Quality Control (MAQC) project shows interand intraplatform reproducibility of gene expression measurements. Nat Biotechnol 24(9):1151-1161. doi:10.1038/nbt1239 